\title{
Utilization of Digital Orthopantomography to Assess Mandibular Asymmetries
}

\author{
OANA MARIA GANSCA ${ }^{1 *}$, SILVIA POP ${ }^{2}$, DORIN NENOVICI ${ }^{3}$, MANUELA CHIBELEAN ${ }^{2}$, EUGEN BUD ${ }^{2}$, \\ OANA BOTOACA ${ }^{4}$, ADRIAN TOHATI ${ }^{5}$, ELINA TEODORESCU ${ }^{6}$, MARIANA PACURAR ${ }^{2}$ \\ ${ }^{1}$ University of Medicine and Pharmacy Science and Technology Targu-Mures, Faculty of Dental Medicine, Department of \\ Pediatric Dentistry, 38 Gh. Marinescu Str., 540139, Targu Mures, Romania \\ ${ }^{2}$ University of Medicine and Pharmacy Science and Technology Targu-Mures, Faculty of Dental Medicine Department of \\ Orthodontics, 38 Gh. Marinescu Str., 540139, Targu Mures, Romania \\ ${ }^{3}$ University of Medicine and Pharmacy Iuliu Hatieganu Cluj Napoca, Faculty of Dental Medicine, Department of Oral \\ Surgery, 16 Mihai Eminescu Str., 400033, Cluj Napoca, Romania \\ ${ }^{4}$ Titu Maiorescu University of Bucharest, Faculty of Dental Medicine, Department of Dental Specialties, 67A Gheorghe \\ Petrascu Str., 031593, Bucharest, Romania \\ ${ }^{5}$ University of Medicine and Pharmacy Science and Technology Targu-Mures, Faculty of Dental Medicine, Department \\ of Preventive and community dental medicine, oro-dental profilaxy, 38 Gh. Marinescu Str., 540139, Targu Mures, \\ Romania \\ ${ }^{6}$ University of Medicine and Pharmacy Carol Davila, Faculty of Dental Medicine Bucharest, Department of Orthodontics, \\ 37 Dionisie Lupu Str., Bucharest, Romania
}

This study used a public domain software, ImageJ, to analyze the orthopantomography in order to diagnose mandibular asymmetry. Analyze was performed on 36 panoramic $x$-rays from two types of patients: one with normal occlusion, and the other with unilateral crossbite. The x-rays were performed in the same center, by the same operator. Image J analyze was based on linear and angular measurements taken from 9 anatomic points marked on the digital images. Conclusions of study have revealed that crossbite patients presented asymmetries in mandibular corpus and in position of the condyles.

Keywords: Mandibular asymmetry, Orthopantomography, Image J, crossbite

Facial asymmetry represents a difference in size or relationship of two sides of the face. Severt and Proffit found different proportions of asymmetry in the upper, middle and lower thirds of the face: 5\%, 36\% and 74\% [1]. Facial asymmetry can exist even in the normal-appearing people, in most cases the left side being larger than the right side. The most significant asymmetries were found in the lower third of the face [2-5]. These could be due by mandibular asymmetry, salivary gland tumors or different inflammatory processes. [6]

Mandibular asymmetry presents high prevalence among patients and it can be an adaptive response to some deviations during function, which can determine asymmetric growth and modelling of different parts of the mandible [7-9]. A difference of more than 2-3 $\mathrm{mm}$ between the sides of the mandible with possible clinical relevance has been considered asymmetry $[10,11]$.

Mandibular asymmetry is diagnosed using a combination of tools: clinical examination combined with photographic analysis, X-rays (lateral and postero-anterior cephalogram and orthopantomography), CT, stereometry, scintigraphy. The panoramic X-ray is commonly used in daily clinical routine, it has minimum radiation exposure and can offer important information about the vertical dimensions and a bilateral view of mandible [12]. It has some limitations: 2D image, magnification and distortion $[13,14]$.

Ramstad et al asserted that measurements on panoramic X-rays are not conclusive and they should be abandoned [14]. Still, several studies have shown that the OPG can be used for vertical and angular measurements if the patient`s head position is correct in the device [15-17]. Many authors, like Habets et. al, Laster et al. showed that the panoramic $\mathrm{X}$-ray is reliable for determining mandibular asymmetries [15, 18-20].

The aim of this study is to evaluate the mandibular asymmetries on digital orthopantomography of two types of patients, patients with and without unilateral crossbite, using a public domain software: ImageJ and Lemos Asymmetry Analysis.

*email: kecsetisilvia@yahoo.com, Phone: +40 740199555 


\section{Experimental part}

Material and methods

In the present study, we analyzed 36 orthopantomographies from 16 patients with mandibular asymmetry and unilateral crossbite occlusion and 20 patients with mandibular asymmetry without any crossbite. The patients' $\mathrm{x}$-rays were selected by analyzing their orthodontic files from the last 2 years, the selected patients exceeded the skeletal development period, the average age being 26. The patients were chosen from the patients` database of the Department of Orthodontics from the University of Medicine and Pharmacy Tîrgu-Mures.

The criteria for the sample of patients with normal occlusion were: moderate facial asymmetry, clinically detectable (with a difference of dimension in the transversal direction $>2 \mathrm{~mm}$ ); no significant medical history: no congenital disease, no neuro-muscular impairment; no history of trauma; no previous orthodontic treatment; normal growth and development; no functional deviation of the mandible.

The criteria for the sample with crossbite occlusion were: unilateral crossbite including at least 2 posterior teeth; mandibular shift to the crossbite side; the absence of development or neuromuscular deformities; no systemic and congenital disease; no previous trauma; no anterior orthodontic treatment.

The criteria for the selected orthopantomographies were: panoramic X-rays performed in Dr X-ray center with the same device (Vatech PaX-i3D); X-rays performed by the same operator with the head oriented parallel to the Frankfurt horizontal plane and the lips in rest position; no artifacts; inclusion of the entire mandible; a good contrast for good structures view; 6 year molars erupted.

Some landmarks were marked on the orthopantomographies, by using the ImageJ software, as following: RPF (right pterygomaxillary fossa); ANS (anterior nasal spine); LPF (left pterygomaxillary fossa); LHC (most cranial point of the left condyle); LGo (left Gonion);

RHC (most cranial point of the right condyle); RGo (right gonion); Pg (Pogonion- midpoint of the mandible visible like a white spot); IP (Interincisive point).

A plug-in was introduced in ImageJ to make automatic measurements: Lemos asymmetry analysis (fig. 1). The image calibration was done by measuring the length of one upper central incisor and introducing the real length from the cast (fig. 2). This analysis is using a distortion factor to adjust the horizontal measurements, which is calculated by measuring the mesio-distal length of the first molars on casts and introducing it into the program (fig. 3).

The following measurements were made with the help of this program:

-Linear measurements, which were morphological and functional (Morphological: RH - ramus height and CL corpus length; Functional (X-rays are performed with the mandible in an advanced position): Pg- MSP (the distance between Pg and medio-sagittal plane); IP-MSP (the distance between interincisale and medio-sagittal plane); CHD (the difference between the heights of the condyles).

-Angular measurement: GA-Gonial Angle.
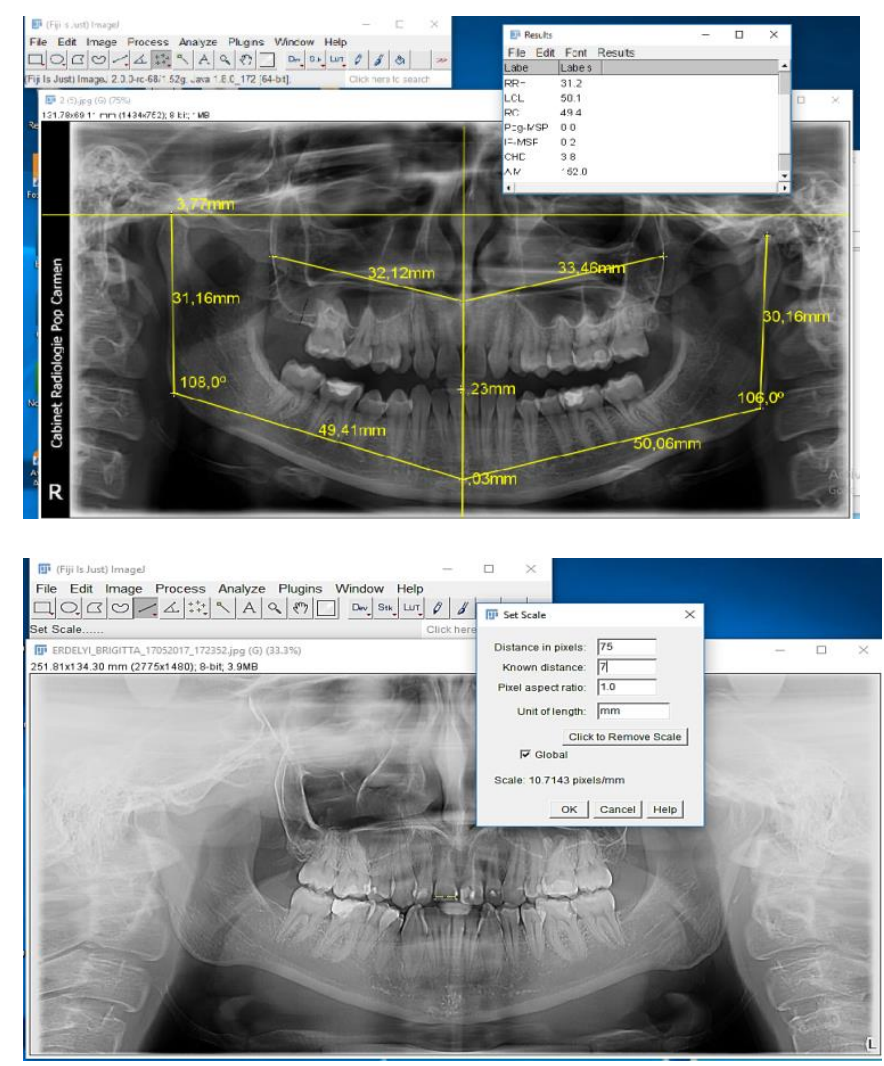

Fig. 1 Automatic measurements using Image J and Lemos asymmetry analysis

Fig. 2 Image calibration by measuring the upper central incisor 
The assessment of mandibular asymmetry was done by using the Ramirez-Yanez method, as follows: non-significant asymmetry: difference between 0-2 mm; light asymmetry: difference between 2-3 mm; moderate asymmetry: 3-5 $\mathrm{mm}$; severe asymmetry: $>5 \mathrm{~mm}$.

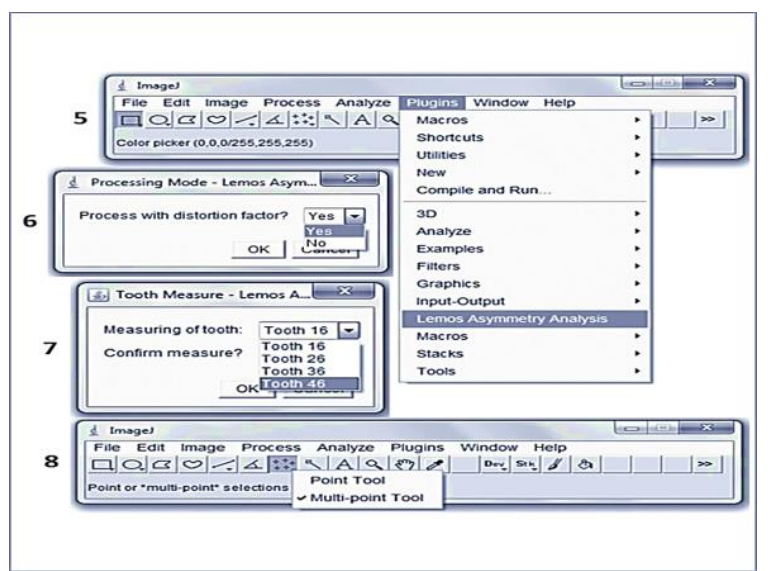

Fig. 3 Establishing the distortion factor

Angular asymmetries have been considered as as follows: non-significant: 0-3 degrees; light: 3-5 degrees; moderate: 5-10 degrees; severe > 10 degrees. The asymmetry degree was determined using the Ramirez-Yanez method [20].

\section{Results and discussions}

The measurements were statistically analyzed, establishing the mean value and the Standard deviation for each sample.

Table 1

MANDIBULAR ASYMMETRY DETERMINATION USING THE RAMIREZ-YANEZ METHOD

\begin{tabular}{|c|c|c|c|}
\hline & & Crossed & $\begin{array}{c}\text { Non- } \\
\text { Crossed }\end{array}$ \\
\hline \multirow{4}{*}{ Difference Ramus height } & Mean \pm SD & $0.73 \pm 3.17$ & $1.41 \pm 2.82$ \\
\hline & $<3$ & 11 & 13 \\
\hline & $3-5$ & 4 & 5 \\
\hline & $>5$ & 1 & 2 \\
\hline \multirow{4}{*}{ Difference Corpus length } & Mean \pm SD & $4.53 \pm 5.41$ & $1.06 \pm 4.97$ \\
\hline & $<3$ & 7 & 7 \\
\hline & $3-5$ & 3 & 7 \\
\hline & $>5$ & 6 & 6 \\
\hline \multirow{4}{*}{ Difference PF-ANS } & Mean \pm SD & $3.95 \pm 2.46$ & $3.67 \pm 1.86$ \\
\hline & $<3$ & 5 & 7 \\
\hline & $3-5$ & 7 & 9 \\
\hline & $>5$ & 4 & 4 \\
\hline \multirow{4}{*}{ PG-MSP } & Mean \pm SD & $2.7 \pm 2.56$ & $2.14 \pm 2.32$ \\
\hline & $<3$ & 10 & 14 \\
\hline & $3-5$ & 4 & 4 \\
\hline & $>5$ & 2 & 2 \\
\hline \multirow{4}{*}{ IP-MSP } & Mean \pm SD & $2.17 \pm 1.85$ & $2.23 \pm 1.83$ \\
\hline & $<3$ & 10 & 14 \\
\hline & $3-5$ & 5 & 5 \\
\hline & $>5$ & 1 & 1 \\
\hline \multirow{4}{*}{ CHD } & Mean \pm SD & $2.60 \pm 2.363$ & $2.70 \pm 1.97$ \\
\hline & $<3$ & 10 & 14 \\
\hline & $3-5$ & 4 & 2 \\
\hline & $>5$ & 2 & 4 \\
\hline \multirow{4}{*}{ Difference Gonial angle } & Mean \pm SD & $2.43 \pm 1.89$ & $2.70 \pm 1.97$ \\
\hline & $3-5$ & 13 & 15 \\
\hline & $5-10$ & 3 & 5 \\
\hline & $>10$ & 0 & 0 \\
\hline
\end{tabular}


Mandibular asymmetry diagnosis is a very complex problem, because it may be caused by several factors: growth problems, condyle hyperplasia, coronoid hyperplasia, hemimandibular elongation or hypertrophy, TMJ disorders, functional factors which lead to bone remodeling etc.

The x-ray is relatively accessible, being used by dentists and orthodontists in their daily practice. Several reports suggested that panoramic X-rays lead to acceptable results and can be used for vertical and angular measurements if the patient`s head is positioned properly in the $\mathrm{x}$-ray apparatus $[21,22]$. Habets et al. suggested one of the first analyses on panoramic radiographs for assessment of mandibular asymmetry developed on a sample of patients with temporomandibular joint problems $[15,24]$ Other authors like Kilic, Uysal adopted this analysis to measure mandibular asymmetry in patients with posterior crossbite [25,26].

The present analysis is different from those studies due to the use of points on the maxilla (ANS, RPF and LPF), which is a stable bone and can represent a reference for tracing the median sagittal plane. Also, we compared in our study the mandibular asymmetry of patients with normal occlusion, with those with unilateral posterior crossbite using Ramirez-Yanez method. According to this method, moderate asymmetry was established as a difference between both sides of the mandible from 3 to $5 \mathrm{~mm}$, whereas severe asymmetry infers more than $5 \mathrm{~mm}$ of difference. For angular measurements, moderate asymmetry was considered a difference between 5-10 degrees, and a severe asymmetry, a difference higher than 10 degrees. According to our study, Kula et al. reported that mandibular asymmetries greater than 2-3 mm affect facial appearance, whereas Skvarilová considered $4-5 \mathrm{~mm}$ as a range for normal asymmetry of facial dimensions $[27,28]$.

In the current study, moderate asymmetries regarding the difference of condyles height position were found on the group of patients without crossbite and more severe asymmetries in the group with unilateral crossbite. Moreover, a greater discrepancy was revealed in the corpus length in the group of patients with unilateral crossbite, with one part bigger, than the one without crossbite. Similar results were found in the study conducted by Lemos et al [29].

No significant differences were found regarding the ramus asymmetry in both groups and the distances between interincisale point or pogonion to midline.

Unlike other studies from the literature, this study is based on the visualization of positional asymmetry of condyles through CHD measurement and skeletal asymmetry through measurements of the ramus (LRH and RRH), offering a differential diagnosis and help regarding adequate treatment [21,24,29,30]. Other studies had investigate the characteristics and the cranial base morphology, in class II division 1 and class II division 2 malocclusions by lateral cephalograms to find a correlation between facial asymmetry and cranial base morphology [31,32], but our technique is less invasive.

\section{Conclusions}

Facial Asymmetry is a craniofacial dysmorphism which affects the facial harmony and patient quality of life and needs a precise diagnosis for a correct orthodontic or orthognathic surgery treatment.

Digital orthopantomography associated with a public domain software can be useful for orthodontists to diagnose a mandibular asymmetry.

Taking into consideration the panoramic X-ray limitations, it is indicated to use the postero-anterior cephalogram or CBCT for more precise measurements.

Measurements on crossbite patients have shown representative asymmetries of mandibular corpus, Pogonion deviation and moderate differences between the positions of the condyles.

In patients with no crossbite, significant differences of condyles height and mild asymmetries of mandibular ramus have been registered.

In both groups moderate asymmetries of Gonial Angle were found.

Comparing the measurements between the mandibular sides, a better development of the right side was noticed.

\section{References}

1.SEVERT, T.R., PROFFIT, W.R., Int J Adult Orthodon. Orthognath. Surg., no. 12, 1997, p. 171-176

2.PECK, S, PECK, L, KATAJ,A M., Angle Orthod., no. 61,1991, p. 3-8

3.PACURAR, M., DRAGOMIR, B., SZALONTAY, A.S., ROMANEC, C., Rev. Chim. (Bucharest), 69, no. 1, 2018, p. 208-213

4.MAEDA, M, KATSUMATA, A, ARIJI, Y, MURAMATSU A, YOSHIDA, K, et al., Oral Surg. Oral Med. Oral Pathol. Oral Radiol. Endod., no. 102,2006, p.382-390.

5.CHEW, MT. Soft and hard tissue changes after bimaxillary surgery in Chinese Class III patients. Angle Orthod., no. 75, 2005, p. 959-963

6.IACOB, A., SIN, A., MOCAN, S., ORMENISAN, A., COMANEANU, R.M., HANCU, V., FULOP, E., TILINCA, M., Rev. Chim. (Bucharest),

67, no 10, 2016, p. 2022-2027

7.PIRTTINIEMI, P., KANTOMAA, T., Acta Odontologica Scandinavica, no. 50, 1992, p. 235-243

8.LIU, C., KANEK, S., SOMA, K., Angle Orthodontist, no. 77, 2007, p. 660-667

9.FROST, H.M., Angle Orthodontist, no. 74, 2004, p. 3-15

10.LU, K.H., Biometrics, no. 21, 1965, p. 491-505

11.KULA, K.A., ESMAILNEJAD, A., HASS, A., Angle Orthodontist, no. 68, 1998, p. 45-52

12.SZUHANEK, C., JIANU, R., SCHILLER, E., BUDURU, S., POPA, A., BUZATU, R., PETRESCU, H.P., GRIGORE, A., Rev. Mat. Plast., 53, no. 4, 2016, p.675-677

13.TRONJE, G., WELANDER, U., MCDAVID, W.D., MORRIS, C.R., Acta Radiol. Diagn. (Stockholm), no. 22, 1981, p. 689-696

REV.CHIM.(Bucharest) $\bullet 70 \diamond$ no $12 \diamond 2019$

4491

http://www.revistadechimie.ro 
14.RAMSTAD, T., HENSTEN-PETTERSEN, O., MOHN, E., IBRAHIM, S.I., J. Oral Rehabil., no. 5, 1978, p. $403-412$

15.HABETS, L.L., BEZUUR, J.N., NAEIJI, M., HANSSON, T.L., J. Oral Rehabil., no. 15, 1988, p. 465-471

16.HABETS, L.L., BEZUUR, J.N., VAN OOIJ, C.P., HANSSON, T.L., J. Oral Rehabil., no. 14, 1987, p. 31, 475-480

17.HABETS, L.L., BEZUUR, J.N., VAN OOIJ, C.P., HANSSON, T.L., J. Oral Rehabil., no. 14, 1987

18.LIUKKONEN, M.L., SILLANMAKI, L., PELTOMAKI, T., Acta Odontologica Scandinavica, no. 63, 2005, p. 168-172

19.LASTER W.S., LUDLOW J.B., BAILEY L.J., HERSHEY H.G., Dentomaxillofacial Radiology, no. 34, 2006, p. 343-349

20.KAMBYLAFKAS P.E., MURDOCK E., GILDA E., TALLENTS R.H., KYRKANIDES S., Angle Orthodontist, no. 76, 2006, p. 388-393

21.JOONDEPH D.R., Am. J. Orthod. Dentofacial Orthop., no. 117, 2000, p. 577-579

22.RAMIREZ-YAÑES, G.O., STEWART, A., CAMPOS, K., Eur J Orthod., no. 33(3), 2011, p. 236-242

23.VASQUEZ, L., GAYDAROV, N., DIN, Y.N., NEDIR, R., BISCHOF, M., et al, Oral Surg. Oral Med. Oral Pathol. Oral Radiol. Endod., no. 105, 2008, p. 61-62

24.GUPTA, S. JAIN, S., J. Ind. Orthod. Soc., no. 46(1), 2012, p. 33-37

25.KILIC, N.,OKTAY, H., Am. J. Orthod. Dentofacial Orthop., no. 133(3), 2008, p.382-387

26.UYSAL, T., SISMAN, Y., KURT, G., RAMOGLU, S.I., Am. J. Orthod. Dentofacial Orthop., no. 136(1), 2009, p. 37-43

27.KULA,,K.A., ESMAILNEJAD, A., HASS, A., Angle Orthodontist, no. 68, 1998, p. 45-52

28.SKVARILOVÁ, B., Acta Chirugia Plastica, no. 35, 1993, p. 173-180

29.LEMOS, S., KATZ, C., HEIMER, M., ROSENBLATT, A., Dental Press J. Orthod., no. 19(3), 2014, p. $52-58$

30.DELEURANT, Y., ZIMMERMANN, A., PELTOMAKI, T., Orthod. Craniofac. Res., no. 11(3), 2008, p. 172-179

31.BECHIR, A., PACURAR, M., BECHIR, E.S., COMANEANU, R.M., CHIBELEAN CIRES, M., MARIS, M., BARBU, H.M., Rev. Mat. Plast., 51, no. 1, 2014, p. 57-61

32.BoiAngiU, R., BENCZE, A., TEOdORESCU, E., MILICESCU, ST. JR., TARMURE, V., PACURAR, M., IONESCU, E., Rev. Chim. (Bucharest), 68 no. 8, 2017, p. 1935

Manuscript received: 4.04 .2019 